\title{
Patient oriented management for the creation of arteriovenous fistula for hemodialysis
}

Tarık Zafer Nursal

Medline Adana Hospital, Department of General Surgery, Adana, Turkey

The study has been presented at the European Surgical Society (ESS) Congress on November $22^{\text {nd }}-24^{\text {th }} 2012$, Istanbul, Turkey.

\section{Address for} Correspondence:

Dr. Tarık Zafer Nursal

Medline Adana Hospital, Department of General Surgery, Adana, Turkey

Phone: +905327763645

e-mail:

tznursal@hotmail.com

Received: 15.06 .2013

Accepted: 12.08 .2013

CCopyright 2013 by Turkish

Surgical Association

Available online at

www.ulusalcerrahidergisi.org
Objective: Hemodialysis access is of paramount importance for end-stage renal failure (ESRF) patients. Creation and maintenance of arteriovenous fistula (AVF) by a dedicated team increases the success and duration of the hemodialysis. The aim of this study is to report a patient oriented standardized surgical technique performed by a single surgeon on the success of AVF creation.

Material and Methods: A single surgeon performed all AVF operations. The records of all patients who were operated for AVF creation without using synthetic grafts through a 3 year period (2009-2011) were included. The patients were examined and operated on by a previously defined standard protocol.

Results: A total of 221 procedures were done for 209 patients. The mean age was $65 \pm 11,4$ years. Immediate function rate was $95.9 \%(n=212)$. Follow-up was possible for 182 patients (82.3\%). For an average follow-up time of 11,3 months, the death rate was $20.8 \%(n=38)$ and the rate of AVF patency was $73.7 \%(n=134)$.

Conclusion: Sustaining patency of AVF is difficult in these systemically deranged patients. A focused approach by a dedicated team will increase the success rate.

Key Words: Arteriovenous fistula, hemodialysis, surgery

\section{INTRODUCTION}

Hemodialysis carries a critical importance for end stage renal failure (ESRF) patients. Although peritoneal dialysis and renal transplantation are both valuable tools, hemodialysis is the most widely used replacement therapy in Turkey as the rest of the world. The most commonly preferred access route is an arteriovenous fistula (AVF), which is used in approximately one-half of the patients undergoing hemodialysis in Turkey (1).

Several factors affect the patency and use in dialysis of a problem free and long lasting AVF. Patient related factors, including age, gender, and presence of systemic diseases, and also the technique used and selection of anatomic region affect $\operatorname{AVF}$ success $(2,3)$.

This study aimed to investigate the effect of a standard surgical approach performed by a single surgeon on the success rate of AVF.

\section{MATERIAL AND METHODS}

All patients in whom hemodialysis treatment for ESRF was planned and who underwent an AVF creation without using a prosthetic graft between 2009-2011 were included into the study. Informed consent was obtained from all patients; an ethical board approval was not taken since only standard approved surgical procedures were used. Patient demographics, technique used and complications were recorded in a prospectively collected database. Mean age of the 209 patients was $65 \pm 11.4$ with a total of 221 AVF creation.

\section{Pre-evaluation for the approach}

Patients referred for surgery were evaluated and operated by a standart approach (4). All patients were informed about the procedures and a written consent was taken. The distal aspect of the non-dominant upper extremity was preferred as much as possible for selecting the vessel and anatomical site. The patients underwent a thorough physical examination including i) Allen test for assessment of vascular supply, ii) an arterial pulse strength of 2 out of 4 in semi-quantative evaluation, iii) venous diameter of at least $1 \mathrm{~mm}$ without tourniquet and at least $2 \mathrm{~mm}$ with tourniquet, regaining original diameter with the release of the tourniquet, iv) visibility of the available vein for at least $5 \mathrm{~cm}$ and easy compressibility; were used as criteria to operate without further evaluation. 
Patients who did not meet the aforementioned positive criteria were sent for a preoperative Doppler ultrasonography guided mapping. Those patients who, by mapping, revealed appropriate vessel properties were operated as those patients showing these properties in physical examination.

\section{Surgical technique}

Patients with appropriate anatomical site and vessel selection were taken to the operation room and local anesthesia was used. A longitudinal incision was preferred for the forearm and a horizontal incision for the antecubital region. Vessels were identified; the vein was mobilized by prevention of angulation and kinking and approximated to the appropriate artery for anastomosis. A longitudinal venotomy of 1-2 mm length was done at the planned anastomosis site; first $100 \mathrm{U} /$ $\mathrm{kg}$ heparin was infused slowly followed by infusion of $10 \mathrm{~mL}$ saline under pressure, using a plastic cannula. The perception of a thrill proximal to vein was targeted at this time. If a thrill was not felt, a 3F or 4F Fogarty catheter was advanced through the venotomy to assess the patency of the vein. If the catheter was lodged, it was advanced, the balloon inflated with dilation of the narrow segment. Then saline was again infused under pressure with evaluation for thrill. If a thrill was still absent another appropriate vein was searched and the operation was terminated in no other veins were detected within the same field.

Upon verification of venous patency, a vessel loop was placed around the artery and a longitudinal arteriotomy was done. The anastomosis was done in a side-by-side fashion with continuous 7/0 polypropylene sutures. The anastomosis diameter was calculated to be no shorter than $6 \mathrm{~mm}$ and no longer than approximately twice the size of the diameter of the vein. Distal part of the vein was ligated and freed of vessel loops. Upon detection of complete fullness, pulse and thrill on the vein the operation was completed. If there was no thrill, proximal vein was checked for angulation or kinking. Both the artery and the vein were catheterized through the distal vein afterwards. If the thrill was still absent the operation was completed. The dressing was applied in a loose manner with no pressure or adhesives directly on the vein.

\section{Follow-up}

Patients were closely observed for the first 30 minutes following surgery in the recovery room. They were sent to the surgical ward after checking for thrill. Elbow flexion was prevented during this period with encouragement of fist exercises that are thought to increase vascular flow. After an observation period of 5-6 hours, they were discharged. They were scheduled for controls in the clinics on postoperative $3^{\text {rd }}$ and $7^{\text {th }}$ days, and were given the numbers for direct telephone access. If the thrill was lost during this period, the patients were taken back to the operating room for re-catheterization via the distal vein was made and if necessary, a new AVF was created more proximally.

The patients were asessed on the postoperative $3^{\text {rd }}, 6^{\text {th }}, 9^{\text {th }}$, and $12^{\text {th }}$ months, besides their visits per request, and every 6 physical evaluation, the nurse or the physician of the hemodialysis unit was contacted and AVF patency was assessed, when even this was not possible, the patient or a relative was interviewed by telephone.

Those patients in whom the AVF was occluded but patency was obtained by interventional radiology were coded as 'patent'. However if the patient required a new AVF they were evaluated as a new record.

Early patency was defined as the presence of thrill and/or murmur in the first 3 days. Long-term patency was defined as the patency of the AVF at the final evaluation.

\section{Statistical analysis}

All analyses were carried out using Statistical Package for the Social Sciences (SPSS) 17.0 (SPSS Inc., Illinois). Parametric valuables were presented as mean \pm standard deviation. Categorical variables were assessed by chi-square test and Fisher's exact test for small groups and continuous variables were evaluated by Student's t-test. Mortality was compared by Kaplan-Meier, log-rank analysis for comparison of anatomical site (elbow vs. wrist). $p<0.05$ was accepted as the limit for significance.

\section{RESULTS}

Two hundred and nine patients $(n=209)$ underwent 221 AVF procedures. The patency rate on discharge was $95.9 \%(n=212)$. One hundred eighty two (82.4\%) of the procedures were available for follow-up. The mean follow-up period was $324 \pm 293$ days, 38 patients (20.8\%) died and the patency rate was $73.7 \%$ $(n=134)$.

The patient population consisted of $56.1 \%(n=124)$ males. Gender was not a significant factor for either patency status on discharge or patency on the last follow up ( $p=0.303$ and $p=0.647$ respectively) (Table 1 ). Gender and death during follow up also did not show a correlation $(p=0.382)$. The site of AVF did not have an effect on early patency $(p=1.000)$. Likewise, the anatomic site preferred for creating the AVF did not affect early patency, long-term results or mortality. Long-term survival analysis did not reveal any differences between the two different anatomic sites (Figure 1).

Patients with early AVF failure were younger than those who had a patent AVF (50.1 \pm 9.5 vs. $59.0 \pm 11.3$ years; $p=0.03)$. Patients with patent long-term AVF did not differ with respect to age from those with failure $(58.7 \pm 11.8$ and $59.9 \pm 9.0$ years, respectively; $\mathrm{p}=0.652$ ).

\section{DISCUSSION}

Patients requiring replacement therapy for end stage renal disease increase by $10 \%$ every year (1). According to data from Turkey, the number of patients in need of this therapy by the end of 2009 is 59,443 (1). In this group the most commonly used replacement therapy is hemodialysis (78.5\%), with the most common route being an AVF. In addition, the number of dialysis sessions have also increased in time, with $70 \%$ of patients undergoing three dialyses per week in 2000, and $90 \%$ of the patients undergoing three dialyses per week in 2009. 
Table 1. Data on variables that are thought to affect early and long-term AVF patency and mortality

\begin{tabular}{|c|c|c|c|c|c|c|}
\hline Variable & Early patency & $\mathrm{p}$ & Long-term patency & $\mathrm{p}$ & Mortality & $\mathrm{p}$ \\
\hline \multicolumn{7}{|l|}{ Gender } \\
\hline Male & $121 / 124(97.6 \%)$ & 0.303 & $77 / 102$ (75.5\%) & 0.647 & $23 / 101(22.8 \%)$ & 0.382 \\
\hline Female & 92/97 (94.8\%) & & $58 / 80(72.5 \%)$ & & $14 / 80$ (17.5\%) & \\
\hline \multicolumn{7}{|l|}{ Anatomic site } \\
\hline Wrist & 153/158 (96.8\%) & 1.00 & $96 / 127$ (75.6\%) & 0.491 & $26 / 126(20.6 \%)$ & 0.89 \\
\hline Elbow & $57 / 59(96.6 \%)$ & & $36 / 51(70.6 \%)$ & & $11 / 51(21.6 \%)$ & \\
\hline
\end{tabular}

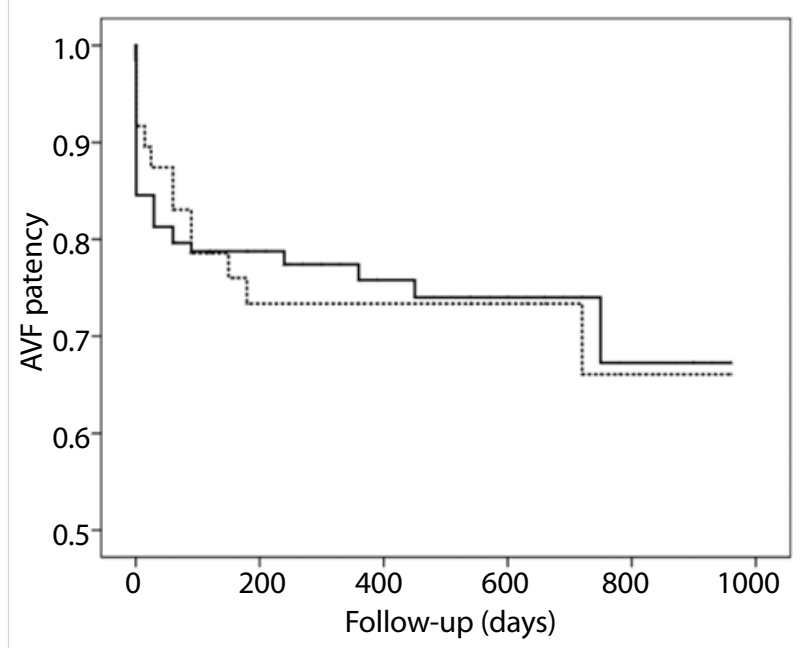

Figure 1. AVF patency according to anatomic site. KaplanMeier method, log rank analysis $(p=0.896)$. Continous line wrist, dashed line elbow

Based on these reasons AVF patency and sufficiency of dialysis emerge as important factors.

Factors effecting AVF success include gender (with higher rates in females) (3). In addition, the preferred vessel, diameter and anatomic location also affect AVF patency. Especially those AVF formed within the more proximal regions where vessel diameter increases show a longer patency (2). However in wide and proximal anastomoses (antecubital or more proximal) mid- or long-term complications are also higher. In proximal AVFs with close proximity to the heart the cardiac output and index increase; therefore venous hypertension, steal syndrome and aneurysms are more likely in these AVFs $(5,6)$. Küçükarslan et al. (7) advocate high radiocephalic anastomosis technique where advantages of both anatomic sites can be used (higher patency of proximal, low complication rate of distal parts).

Contrary to previous reports, this series did not show any effect of gender, age or anatomic site of AVF on long-term patency. Actually older patients showed a higher early success rate. Thorough pre-evaluation, tailored therapy, choice of anatomic site, and diligent technique are all thought to contribute to the loss of difference between previously reported to be significantly different sub-groups.
Arteriovenous fistula patency rates vary between reports $(2-4,6,7)$. This might be the result of contribution of more than one surgeon performing the procedure or utilization of different techniques. Inter-center education and experience differences might also have an effect on the results. Moreover, non-documented or non-noticed anatomic and demographic patient factors can affect these results. Therefore, comparison of different approaches and technique by different studies is not a reliable method.

The results of a previous study, which was done within the same geographic region, with presumably similar patient demographics and a team of surgeons with similar education including the author of this report by using the same AVF technique described, have been re-evaluated. (4). The previous study included 70 patients and the patency rate was $66 \%$ in a mean follow up period of 7 months, whereas this study showed a higher patency rate (74\%) in a longer follow up period (mean 11 months). This approximately 10\% difference in patency rates is thought to be the result of having one surgeon performing all the surgeries in the current series in contrast to a group of surgeons performing the procedure in the previous report.

\section{Study Limitations}

Although the database was collected prospectively, the follow-up rate and records of some criteria were not fully completed. Besides, there is no control group to compare the patency rates.

As emphasized in the discussion section comparison to a study performed in a similar geographic area with a similar surgical team might lead to some suggestions (4).

\section{CONCLUSION}

Unfortunately, creation of arteriovenous fistulas does not receive the required attention. It is used as a learning tool for beginners, to perform correct vessel anastomosis in coronary artery by-pass procedures for cardiothoracic surgeons or organ transplantation units. However, creation of AVF that has a direct effect on the hemodialysis treatment of many ESRF patients and the operation should be performed by specific surgeons/teams after serious education after completion of the learning curve. It is shown that factors like age, gender and anatomic site of AVF, which were reported to have a significant effect in previous studies, do not have a significant effect on 
patency if the procedure is done by a dedicated surgeon/team on this field.

Conflict of Interest: No conflict of interest was declared by the author.

Peer-review: Externally peer-reviewed.

Informed Consent: Written informed consent was obtained from all patients who participated in this study.

\section{REFERENCES}

1. Süleymanlar G, Seyahi N, Altıparmak MR, Serdengeçti K. Current status of renal replacement therapy in Turkey: 2009 report from Turkish Nephrology Society. Turk Neph Dial Transpl 2011; 20: 1-6.

2. Sözüdoğru AN, Cangel U, Eryüksel B, Beşirli K, Kavak MK, Çoşkun $\mathrm{H}$. Short and long term results of arteriovenous fistulas created for hemodialysis: Retrospective clinical study. GKDC dergisi 1999; 7: 135-139.

3. Acıpayam M, Zor H, Yıldız GR, Uncu H, Çetinoğlu M, Halıcı Ü, ve ark. Factors effecting patency of arteriovenous fistulas created for hemodialysis: Evaluation of three-years. Türk GKDC Dergisi 2013; 21: 59-62.

4. Nursal TZ, Oguzkurt L, Tercan F, Torer N, Noyan T, Karakayali H, et al. Is routine preoperative ultrasonographic mapping for arteriovenous fistula creation necessary in patients with favorable physical examination findings? Results of a randomized controlled trial. World J Surg 2006; 30: 1100-1107. [CrossRef]

5. İbrişim E, Öcal A, Yavuz T, Nazlı C, Sezer T, Düver H, Kutsal A. The effects of Brescia-Cimino and radiosephalic type arteriovenous fistula on cardiac output and cardiac index . üllerin kardiak output ve kardiak indeks üzerine etkileri. Turk Neph Dial Transpl 2001; 10: 11-13

6. Çolak MC, Dişli O, Erdil N, Cihan HB, Battaloğlu B. Short and long term complications of arteriovenous fistula created for hemodialysis at Turgut Özal Medical Center Cardio-thoracic Surgery Clinics. İnönü Üniversitesi Tıp Fakültesi Dergisi 2011; 18: 160-163.

7. Küçükarslan N, Özal E, Yavuz İ, Kürklüoğlu M, Arslan M, Tatar H. Three years of experience on the creation of high radial arteriovenous fistula: Surgical technique, functionalty, complications related to location. Turkish JVasc Surg 2006; 15: 31-36. 